\title{
Recent changes in the number of spoon-billed sandpipers Calidris pygmaea wintering on the Upper Gulf of Mottama in Myanmar
}

\author{
Pyae-Phyo Aung, Saw Moses, Nigel A. Clark, Guy Q.A. Anderson \\ Geoff M. Hilton, Graeme M. Buchanan \\ Christoph Zöckler and Rhys E. Green
}

\begin{abstract}
The spoon-billed sandpiper Calidris pygmaea, a migratory Arctic-breeding shorebird, is one of the rarest birds and its population has declined since the 1970s. We surveyed its most important known wintering area in the Upper Gulf of Mottama in Myanmar to estimate recent (2009-2016) changes in its numbers there. The total number of small shorebirds present in the Upper Gulf was counted and the proportion of them that were spoon-billed sandpipers was estimated from sample scans. These two quantities were multiplied together to give the estimated number of spoon-billed sandpipers in each of 4 years. Total numbers of combined small shorebird species tripled from 21,000 to 63,000 between 2009 and 2016 , coincident with efforts to reduce hunting pressure on waterbirds. However, the proportion of small shorebirds that were spoon-billed sandpipers declined and their estimated absolute numbers fell by about half, from 244 to 112 individuals. It is probable that loss of intertidal habitat and shorebird hunting elsewhere on the migration route of the spoon-billed sandpipers wintering at Mottama is causing a continued decline, although this is occurring at a less rapid rate than that recorded from Arctic Russia before 2010. The number of spoon-billed sandpipers wintering on the Upper Gulf of Mottama remains the highest single-site total for this species from any known wintering site. Preventing resurgence of illegal shorebird hunting and ensuring long-term protection of the intertidal feeding habitats and roost sites in the Gulf are high priorities if extinction of this species is to be averted.
\end{abstract}

Pyae-Phyo Aung and SAW Moses Biodiversity and Nature Conservation Association, Yangon, Myanmar

Nigel A. Clark British Trust for Ornithology, Thetford, UK

Guy Q.A. Anderson and Graeme M. Buchanan RSPB Centre for Conservation Science, Sandy, UK

Geoff M. Hilton Conservation Science Department, Wildfowl \& Wetlands Trust, Slimbridge, UK

Christoph Zöckler ArcCona Consulting, Spoon-billed Sandpiper Task Force, Cambridge, UK

RHYS E. GREEN (Corresponding author) Department of Zoology, University of Cambridge, Downing Street, Cambridge, UK. E-mail reg29@cam.ac.uk

Received 16 February 2018. Revision requested 12 April 2018.

Accepted 2 May 2018. First published online 7 September 2018
Keywords Calidris pygmaea, intertidal, Myanmar, population monitoring, shorebird, spoon-billed sandpiper, Upper Gulf of Mottama, wintering

\section{Introduction}

The spoon-billed sandpiper Calidris pygmaea is categorized as Critically Endangered on the IUCN Red List because of its small global population size and rapid population decline (Zöckler et al., 2010a; BirdLife International, 2017). In late summer, its population migrate from breeding grounds on coastal tundra in the Arctic and sub-Arctic zones of the Chukotka Autonomous Okrug and northern Kamchatka Kraj in Russia, through the southern Russian Far East, North Korea, South Korea, China and Japan to wintering areas on intertidal mudflats in southern China, Thailand, Myanmar, Viet Nam, Malaysia and Bangladesh (Clark et al., 2014; Zöckler et al., 2016).

The largest known wintering population of spoon-billed sandpipers is in the northern part of the Gulf of Mottama (also known as the Bay of Martaban), a large estuary in Myanmar. Studies at this site in 2009 and 2010 estimated the numbers of spoon-billed sandpipers and other shorebirds and also showed that spoon-billed sandpipers were killed frequently by hunters who were netting larger shorebird species for food (Zöckler et al., 2010b). All shorebird species are legally protected under the Wildlife Act of Myanmar, which prohibits their killing or capture, but the law is not fully implemented. Beginning early in January 2010 and continuing since then, efforts have been made to reduce mortality by assisting local authorities to implement bans on shorebird hunting and helping former bird hunters to switch to alternative livelihoods, especially fishing (Htin Hla \& Eberhardt, 2011; Clark et al., 2014).

These actions appear to have been largely successful, with recent surveys detecting little evidence of shorebird trapping gear in the Gulf of Mottama and other sites in Myanmar and Bangladesh (Aung et al., 2014, 2015, 2016, 2017). However, there continue to be reports of mortality of spoon-billed sandpipers caused by hunting and entanglement in fishing nets in other parts of the non-breeding range, including China (Pain et al., 2011; Martinez \& Lewthwaite, 2013; Clark et al., 2014; Martinez, 2016; Peng et al., 2017). In 
addition, conversion of intertidal areas for human use, especially in the Yellow Sea region of South Korea and China, is having significant effects on survival and population size of migratory shorebirds along the East Asian-Australasian flyway, where more shorebird species are declining than in any other flyway (Kirby, 2010; Mackinnon et al., 2012; Piersma et al., 2015, 2017). The spoon-billed sandpiper is thought to be among the species most threatened by these changes. A comparison of a compilation of recent counts of wintering spoon-billed sandpipers (Zöckler et al., 2016) with a markresighting estimate of the world population of the species (Clark et al., 2018) suggests that the winter locations are known for only c. half of the population. Based on wintering population estimates from Zöckler et al. (2016), the Upper Gulf of Mottama is the most important known wintering site. It holds c. two-thirds of the global total of sandpipers counted in winter (Zöckler et al., 2016) and one quarter of the winter population estimated by mark-resighting (Clark et al., 2018). Counting spoon-billed sandpipers at any wintering site is challenging because they are rare and usually dispersed within large flocks of other small shorebirds, especially the similarly coloured and sized red-necked stint Calidris ruficollis. In the Upper Gulf of Mottama, complete direct counts of spoon-billed sandpipers are impractical because of the large numbers of other small shorebirds that must be checked, the large size of the intertidal area, day-to-day variation in the extent and location of foraging habitat exposed at low tide and frequent changes in the location of high-tide roosts. Roosts are often on very soft substrates, making it impossible to approach them before the birds leave on the falling tide. A highly dynamic tidal flow in the estuary restricts the availability of areas where boats can be beached at low tide so that surveys of foraging birds can be carried out safely on foot.

Here we report recent estimates of the numbers of spoonbilled sandpipers in the Upper Gulf of Mottama made using methods comparable to those of Zöckler et al. (2010b). To circumvent the difficulties mentioned above, our surveys determined (1) the total number of small shorebirds present in the Upper Gulf, without counting the different species separately, and (2) the proportion of small shorebirds that were spoon-billed sandpipers in sample scans. The number of spoon-billed sandpipers was then estimated as the product of these two quantities. Using this method, Zöckler et al. (2010b) estimated there were 200 spoon-billed sandpipers in the Upper Gulf of Mottama in 2010 and considered that there could be c. 20 more in other parts of the Gulf, based on sightings in that and other years. This estimate (220 individuals) was used in a later global compilation of recent winter population assessments (Zöckler et al., 2016). However, there has been no assessment of possible changes in the wintering population at the Gulf of Mottama since measures were introduced to restrict hunting. Our objective is to assess the recent trend in the spoon-billed sandpiper population wintering in the Upper Gulf of Mottama, and changes in the proportion of small shorebirds that are spoon-billed sandpipers, by combining the data for 2010, previously reported by Zöckler et al. (2010b), with results for 2009 and 4 more recent years.

\section{Study area}

The Gulf of Mottama (or Martaban) lies in Yangon Region, Bago Region and Mon State in Myanmar, at the mouth of the Sittaung River. It is a large funnel-shaped estuary c. $100 \mathrm{~km}$ wide at the southern end, covering a total area of c. $2,500 \mathrm{~km}^{2}$. Its tidal cycle is extremely pronounced in speed and amplitude (6-7 $\mathrm{m}$ tidal range), causing a powerful bore phenomenon that is highly unusual in the region and makes this one of the most dynamic estuaries in the world, with constant sediment redistribution, channel-shifts, erosion and accretion on a large scale. We surveyed part of the Gulf north of latitude $17^{\circ} \mathrm{N}$ (Fig. 1). We selected this part because only small numbers of spoon-billed sandpipers have been recorded in the parts further to the south (Zöckler et al., 2010b) and because its large tracts of intertidal mud are accessible by fishing boats from villages on the eastern side of the Gulf.

The dynamic nature of the estuary means that the location and extent of intertidal flats change substantially from month to month. This dynamism is illustrated by the movement of the main channel of the Sittaung from the east to the west side of the estuary following a cyclone in 2008. To produce an estimate of the extent of the intertidal zone relevant to our study period, we analysed Landsat 8 satellite images from spring 2016. Visual inspection of Landsat 8 images showed that the mudflats were stable during this time. The area of mud between high tide on 13 February 2016 and low tide on 17 April 2016 was estimated from changes in the radiance in atmospherically corrected band 5 between the Landsat 8 images from these dates. This near infra-red band is useful for mapping shorelines (Barsi et al., 2014). The radiance values associated with exposed mud were determined from visual inspection of both images, and comparison of the extent of mud was used to identify the intertidal area. At that time, we estimated that the intertidal zone within our survey area covered $217 \mathrm{~km}^{2}$ (Fig. 1). Part of the Gulf within Mon State, overlapping our study area and covering $425 \mathrm{~km}^{2}$, was site designated in 2017 under the Ramsar Convention on Wetlands 1971 (Ramsar Site no. 2299).

\section{Methods}

\section{Fieldwork}

We report scan surveys to estimate spoon-billed sandpiper numbers in the Upper Gulf of Mottama during January or 


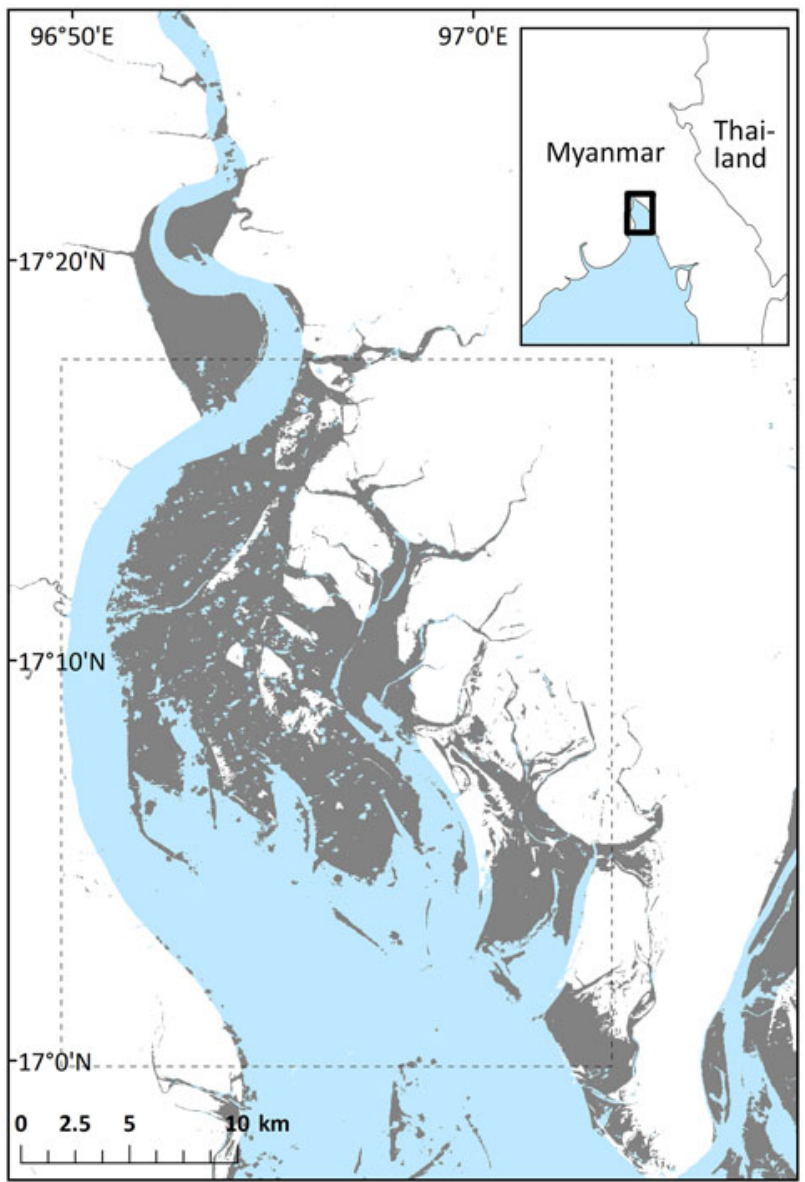

FIG. 1 The Upper Gulf of Mottama, with its location within Myanmar in the inset. The rectangular box on the main map defines the study area, within which we surveyed spoon-billed sandpipers Calidris pygmaea. The intertidal zone in spring 2016 (the area between high tide on 13 February 2016 and low tide on 17 April 2016) is shown by the dark grey shading.

February, or both, of 2009, 2010, 2011, 2012, 2015 and 2016. Surveys were in these months because migratory overwintering shorebirds were likely to have all arrived by then and few birds would be expected to have departed on their return migration. Within this period, visits were timed to cover the highest series of spring tides because the boats we used had free access over all of the intertidal flats only at high spring tides, and because shorebirds are likely to be concentrated at high tides and to gather in large flocks that we would be less likely to miss when attempting to count the total numbers of small shorebirds (see below).

The survey team was transported to as many parts of the study area as possible in shallow-draft fishing boats, which were grounded on the mud in the intertidal zone at low tide to allow observation of birds from the boat and on foot. In this way, we were able to conduct scan surveys throughout the daylight period of tidal cycles and at a wide range of elevations relative to the high and low water marks. The study area was divided into sections, which we call blocks, in each of which we spent 1-2 days surveying before moving to another. Blocks were determined according to tidal and wind conditions, the number of observers and the locations of high-tide roosts during the visit, and therefore differed among years. Groups of 2-4 observers walked the intertidal zone, diverging from the place where the boat was grounded, and also viewed birds from the boats, especially when the tide was high. Each group of observers included individuals experienced in shorebird identification, who scanned flocks of resting and foraging small shorebirds using a telescope. The observers were not the same individuals in all years, but one observer (NAC) participated in all the surveys reported here and several other individuals participated in two or more of the surveys. The small-bodied shorebird species (body weight $<80 \mathrm{~g}$ ) present, in addition to spoon-billed sandpipers, mostly comprised calidrid sandpipers (curlew sandpiper Calidris ferruginea, broadbilled sandpiper Calidris falcinella and red-necked stint) and plovers (greater sandplover Charadrius leschenaultia, lesser sandplover Charadrius mongolus, Kentish plover Charadrius alexandrinus and little ringed plover Charadrius dubius). These species tended to feed and roost in mixedspecies flocks and were readily distinguished at a distance on the ground and in flight from the larger-bodied shorebird species $(>120 \mathrm{~g}$ ) present (great knot Calidris tenuirostris, Tringa spp., Limosa spp. and Numenius spp.). However, separate identification and counting of all spoon-billed sandpipers and other species was not possible.

A scan consisted of a search by one observer through a group of small shorebirds, at the end of which the numbers of small shorebirds of each species were recorded, together with the date and time of the record and the location, with a global positioning system. Often the observer spoke the numbers of birds of each species checked at intervals within the scan, whilst viewing the birds through a telescope, and these were written down by another group member. An individual small shorebird was included in the scan record only if it was seen well enough to be sure whether it was a spoon-billed sandpiper or not, and observers were trained to spend enough time observing each bird do this accurately. Training was given by the experienced observers to achieve consistency. Some scans were conducted by inexperienced observers for training purposes and checked by a repeat survey of the same flock by an experienced observer. Results from these duplicated training scans were discarded. Individual scan records covered varying numbers of birds, from a few individuals to $>1,000$. Because of this variation, and because it took longer per bird to check species identity at a long distance or under difficult light conditions, the scans were not of fixed duration or of a fixed area. During our scan counts we almost certainly scanned the same individuals more than once at different stages of the tidal cycle 
and on different days. However, the sole objective of the scan counts was to estimate the proportion of small shorebirds that were spoon-billed sandpipers, so this only introduces pseudo-replication into our estimates, rather than biasing them. Because our survey period in a given year was short, it is unlikely that much movement of birds occurred among the survey blocks.

In addition, we made counts of the total number of small shorebirds in each block in 2009, 2010, 2015 and 2016, mostly by estimating the size of large flocks of shorebirds at roosts, when they were flying between feeding areas and high-tide roosts or when they were flushed by raptors. In these years, we consider that coverage of the Upper Gulf was sufficient to provide a valid count of the small shorebird total, whereas in 2011 and 2012 coverage for full counting was incomplete for logistical reasons. Estimates were made using standard methods in which counts of individuals in parts of flocks were made and scaled up by eye to give the flock total. These estimates were made by an observer (NAC) with substantial previous experience in using this method elsewhere. It was usually not possible to identify birds to species when making these counts, but it is likely that nearly all the birds counted were of the same set of small shorebird species targeted by the scans because these species are markedly smaller than the smallest of the larger shorebird species. An estimate of the total number of small shorebirds present in each block was obtained by combining results from these counts across groups of observers and at different times and discussing the location and timing of different records to reduce the risk of double counting.

\section{Analysis}

We followed the approach used by Zöckler et al. (2010b) in calculating the number of spoon-billed sandpipers. The principle of the method is that the estimated number of sandpipers in a survey year is given by the product of the estimate of the proportion of small shorebirds that are spoon-billed sandpipers and the count of small shorebirds. We multiplied the proportion of small shorebirds that were spoon-billed sandpipers, obtained from the scan data pooled across blocks for a given year, by the total number of small shorebirds estimated from the shorebird counts summed across survey blocks for that year. To assess trends in the proportion of small shorebirds that are spoon-billed sandpipers and the estimated number of spoon-billed sandpipers, we performed ordinary least squares regressions of year-specific logit-transformed proportions of small shorebirds that were spoon-billed sandpipers and $\log _{\mathrm{e}}$-transformed estimated numbers of sandpipers on the decimal calendar year of the midpoint of the survey period. We calculated $95 \%$ confidence intervals of year-specific estimates of proportion and number by bootstrapping. To do this, we grouped our scans into bootstrap units comprising consecutive scan records by a single group of observers within a single period between two high tides. We combined sets of scans adjacent in time to ensure that each bootstrap unit included at least 50 small shorebirds. We then drew a bootstrap sample of size $n$ bootstrap units at random, with replacement, from the $n$ units available in each year and performed the calculations of the proportion of small shorebirds that were spoon-billed sandpipers in a given year and the estimated number of spoon-billed sandpipers as described above. We repeated this procedure 10,000 times for a given year and took the bounds of the central 9,500 bootstrap values to define the $95 \%$ confidence limits of the estimated proportion or population estimate for that year. Having done these calculations separately for all calendar years, we aligned the 10,000 bootstrap estimates for each year in random order and fitted the two regression models described above to estimate trends of proportion and number in relation to calendar year. We took the bounds of the central 9,50o bootstrap values of the regression slopes to define their $95 \%$ confidence limits.

\section{Results}

The $95 \%$ confidence interval of the slope of the ordinary least squares regression of logit-transformed proportion of scanned small shorebirds that were spoon-billed sandpipers on decimal calendar year did not overlap zero (slope $=-0.2240,95 \% \mathrm{CI}-0.3001-0.1105)$. The proportion of scanned small shorebirds that were spoon-billed sandpipers thus declined significantly and markedly, c. sixfold, between 2009 and 2016 (Table 1, Fig. 2). The total count of small shorebirds increased c. three-fold, from 21,00o to 63,000, between 2009 and 2016 (Table 1). The correlation between the natural logarithm of the total count of small shorebirds and calendar year was high, indicating a statistically significant increase, with little variation in annual counts around the trend (Pearson correlation $r=0.955, t_{2}=$ 4.53, two-tailed $\mathrm{P}=0.045$ ). The slope of the least squares regression of the natural logarithm of the small shorebird count on year was 0.144 , which indicates a mean exponential population multiplication rate of $e^{0.144}=1.155(15.5 \%$ increase per year).

However, the increase in the total count of small shorebirds was not sufficient to cancel out fully the decline in the proportion of small shorebirds that were spoon-billed sandpipers. Hence, the estimated number of spoon-billed sandpipers, calculated as the product of the total small shorebird count and the proportion that were spoon-billed sandpipers, declined by c. half, from 244 to 112 individuals (Table 1, Fig. 3). The 95\% confidence interval of the slope of the ordinary least squares regression of $\log _{\mathrm{e}}$-transformed spoon-billed sandpiper population estimate on decimal 
TABLE 1 Results of scan surveys for spoon-billed sandpipers Calidris pygmaea in the Upper Gulf of Mottama 2009-2016 (Fig. 1).

\begin{tabular}{llllllll}
\hline & $\begin{array}{l}\text { Earliest \& } \\
\text { latest survey } \\
\text { dates }\end{array}$ & $\begin{array}{l}\text { No. of small } \\
\text { shorebirds } \\
\text { scanned }\end{array}$ & $\begin{array}{l}\text { No. of spoon- } \\
\text { billed sandpipers } \\
\text { scanned }\end{array}$ & $\begin{array}{l}\text { Number of } \\
\text { bootstrap } \\
\text { units }\end{array}$ & $\begin{array}{l}\text { Proportion of } \\
\text { spoon-billed } \\
\text { sandpipers }\end{array}$ & $\begin{array}{l}\text { Total small } \\
\text { shorebird } \\
\text { count }\end{array}$ & $\begin{array}{l}\text { Estimated spoon- } \\
\text { billed sandpiper } \\
\text { population }\end{array}$ \\
\hline 2009 & 13-16 January & 4,022 & 46 & 19 & 0.0114 & 21,325 & 244 \\
2010 & 1-2 February & 34,250 & 195 & 99 & 0.0057 & 35,000 & 199 \\
2011 & 19-21 January & 8,462 & 33 & 51 & 0.0039 & ND & ND \\
2012 & 24 January-11 February & 32,098 & 202 & 175 & 0.0063 & ND & ND \\
2015 & 17-23 January & 67,234 & 163 & 215 & 0.0024 & 64,183 & 156 \\
2016 & 7-13 February & 52,754 & 93 & 280 & 0.0018 & 63,260 & 112 \\
\hline
\end{tabular}

${ }^{\star} \mathrm{ND}$, not determined.

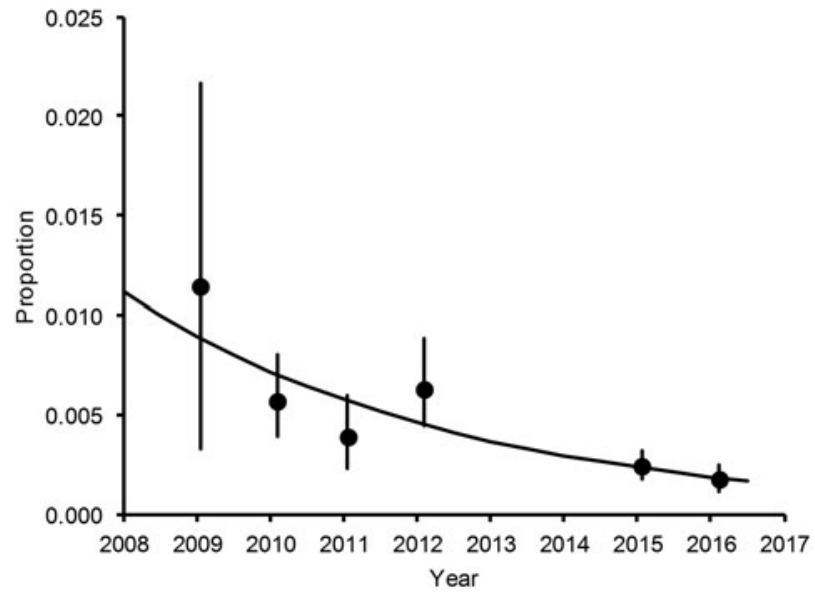

Fig. 2 Proportion of spoon-billed sandpipers in scan surveys of small shorebirds in winter in the Upper Gulf of Mottama (Fig. 1) in relation to the year of the survey. Plotted points are overall proportions for each of six winter surveys. Vertical lines are $95 \%$ bootstrap confidence limits. The curve is the back-transformed relationship logit (proportion) $=445.2393-0.22396{ }^{*}$ calendar year fitted by ordinary least squares to the logit-transformed annual values.

calendar year overlapped zero marginally (slope $=-0.0906$; 95\% CI -0.1710-+0.0352). This trend estimates the mean annual population growth rate and is suggestive of a decline, being equivalent to a mean annual decline of $8.7 \%$. It is also equivalent to an overall decline during 2009-2016 of $47 \%$, but with substantial uncertainty (95\% CI 70\% decline to $28 \%$ increase). Despite the wide confidence interval, only $6.6 \%$ of bootstrap replicates had a positive population trend, so the results are sufficiently close to demonstrating a population decline, using a conventional significance test, to be of concern.

\section{Discussion}

The observed large increase in numbers of small shorebirds counted during 2009-2016 coincides with a reduction in

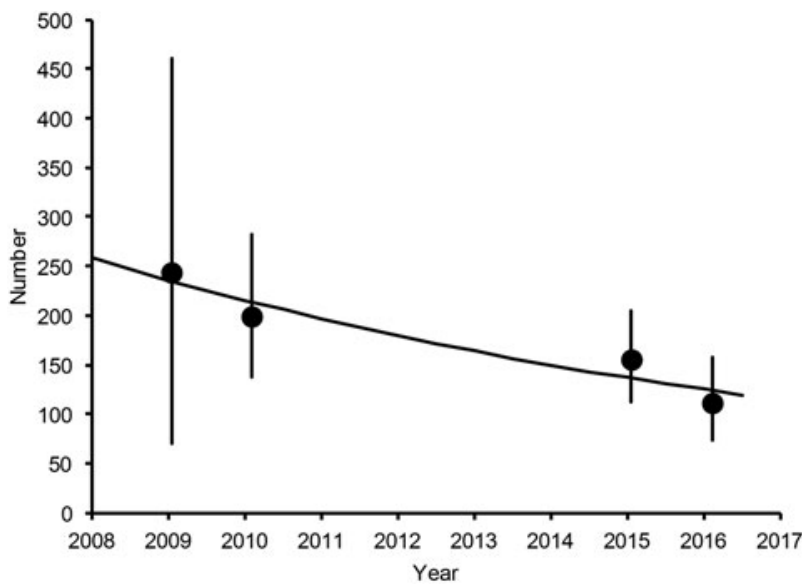

FIG. 3 Estimated population of spoon-billed sandpipers in winter in the Upper Gulf of Mottama (Fig. 1) in relation to the year of the survey for the four winters for which both proportions of spoon-billed sandpipers and total counts of small shorebirds were available. Plotted points are population estimates for each winter survey. Vertical lines are $95 \%$ bootstrap confidence limits. The curve is the back-transformed relationship $\log _{e}($ population $)=187.4045-0.09056 *$ calendar year fitted by ordinary least squares to the $\log _{\mathrm{e}}$-transformed annual values.

hunting pressure on waterbirds in the Gulf of Mottama occasioned by the implementation of bird hunting bans and efforts of conservation agencies and local authorities to assist former bird hunters to switch to alternative livelihoods (Htin Hla \& Eberhardt, 2011; Aung et al., 2015, 2016, 2017). Although we are convinced that this increase has occurred, the nature of the fieldwork used to determine the small shorebird total does not allow us to estimate the precision of each of the counts or to evaluate sources of error. It is certainly possible that some flocks or roosts were missed and that the estimation of the size of large flocks of shorebirds by eye was subject to error. Independent small shorebird counts in the same winter month by separate teams of observers would have been needed to assess these uncertainties, and we did not have the resources for this. Against this caveat about the apparent increase in small shorebirds, we 
note that counts for individual years deviated only slightly from the fitted regression of small shorebird count on year, which suggests that possible errors were consistent across survey years and would not bias the spoon-billed sandpiper trend estimate.

We found strong evidence that the proportion of small shorebirds that were spoon-billed sandpipers declined, and moderately strong evidence that absolute numbers of spoon-billed sandpipers in the Upper Gulf declined during the same period. Although we could only estimate the absolute population size of the spoon-billed sandpiper in the 4 years for which we had a count of all small shorebirds, the data on the proportion of small shorebirds that were spoon-billed sandpipers in 2 additional years were also consistent with a decline. However, the mean annual population growth rate we estimated for the Upper Gulf of Mottama $(r=-0.0906)$ indicated a considerably less rapid decline than that reported by Zöckler et al. (2010a), based upon counts at four well-monitored sites on the breeding grounds in Arctic Russia during 2002-2009 ( $r=-0.3065)$. This difference corresponds to a mean annual rate of decline of $8.7 \%$ per year for Mottama during 2009-2016 compared with $26.4 \%$ per year for Russia during 2002-2009. If the rate of decline estimated for Russia had continued and applied to the Upper Gulf of Mottama, the number of spoon-billed sandpipers there would have declined by $88 \%$ during 2009-2016, instead of the $47 \%$ decline over that period estimated from our regression (Fig. 3). Annual counts of breeding pairs at a consistently monitored part of Meinypilgyno, the best-studied of these four breeding sites, during 20032009 also indicated a statistically significant decline (population growth rate $r=-0.2134,95 \%$ CI from a Poisson regression $-0.3267--0.1001$ ) at a similar rate to that for the four sites in a similar period, but continued monitoring of the same part of Meinypilgyno from 2009 until 2016 showed that the breeding population there then became approximately stable $(r=-0.0030,95 \%$ CI $-0.1114-+0.1055$ : Tomkovich et al., 2016). Because of the wide confidence intervals of the estimated mean annual population growth rates for both Myanmar and Russia, the population growth rates at the two sites during 2009-2016 were not significantly different ( $8.7 \%$ decline per year for Mottama vs 0.3\% decline per year for Meinypilgyno). Conservation measures that may account for a recent slowing of the rate of decline include increased efforts to reduce losses to hunting in the non-breeding season at Mottama and elsewhere and a headstarting programme at Meinypilgyno that began in 2012. Spoon-billed sandpiper eggs were removed from nests and artificially incubated (Clark et al., 2014). The chicks were then reared until fully grown, and released near the breeding site. Up to $2017,>140$ young sandpipers have been headstarted and some have returned to the site and bred. Other factors may also have changed between the period of decline and stability, but there are no comparable measurements of other potential drivers at a population level before and after the change.

If the wintering population of spoon-billed sandpipers in the Upper Gulf of Mottama really declined by almost half during 2009-2016 this may reflect continuing effects of hunting and habitat loss elsewhere along the migration route of this part of the population. The species migrates through the Yellow Sea (China, North Korea, South Korea), where considerable loss of intertidal habitats caused by land claim for human use has occurred and is continuing (Mackinnon et al., 2012; Peng et al., 2017). Hunting of shorebirds using mist-nets, poison baits and other methods also continues in many parts of South China and South-east Asia used as migration staging areas (Martinez \& Lewthwaite, 2013; Martinez, 2016), and shorebirds also become entangled in static fishing nets in these areas. Another possibility is that the spoon-billed sandpiper population of the Gulf of Mottama as a whole has not declined, but that part of the population has moved to areas of the Gulf south of $17^{\circ} \mathrm{N}$, which were not covered by our surveys, because of changes in the distribution of intertidal mud and sand flats. However, if such a shift has occurred, it is not clear why it has not also had a similar negative effect on the numbers of small shorebirds of other species in the Upper Gulf. At present, we are unable to quantify changes over time in the extent and quality of intertidal spoon-billed sandpiper habitats, using remotely sensed data, sufficiently accurately to exclude this possibility.

The Upper Gulf of Mottama continues to be a key wintering area for spoon-billed sandpipers, and the number wintering there remains the highest single-site total for this species from any known wintering site (Zöckler et al., 2016). The Gulf as a whole is also an important site for many other species of waterbirds (Zöckler et al., 2014) and our counts of small shorebirds indicate that the importance of the Upper Gulf for these has increased. Future conservation efforts for spoon-billed sandpipers and other waterbirds there should focus on preventing any resurgence of illegal shorebird hunting, minimizing accidental captures in fishing gear and ensuring long-term protection of the intertidal feeding habitats and safe roosting areas. Steps towards achieving these objectives have been made recently, with much of the eastern half of the Upper Gulf (within Mon State) being designated as a Ramsar site. It is hoped that Ramsar designation will be extended to the western portion of the Upper Gulf (Bago State) in the near future.

Acknowledgements RSPB, the Wildfowl \& Wetlands Trust and the BBC Wildlife Fund helped to fund the surveys. Leica Camera AG provided optical equipment through the Wildfowl \& Wetlands Trust. We are grateful to the boatmen, without whom the surveys would have been impossible, and the many surveyors from Myanmar and elsewhere who assisted us. Two anonymous reviewers provided constructive comments. 
Author contributions Survey design: NAC; survey arrangements: PPA and SM; fieldwork: all authors; analysis: NAC, GQAA and REG; satellite imagery analysis: GMB; writing: REG.

\section{Conflicts of interest None.}

Ethical standards This paper is based upon results obtained using non-intrusive research methods that were compliant with the Oryx Code of Conduct.

\section{References}

Aung, P.-P., Moses, S., Zaw, M.T., Naung, H.P., Htet, M.T. \& Aung, N.O.O. (2014) Monitoring Programme for Critically Endangered Spoon-Billed Sandpiper on its Most Important Wintering Grounds in Myanmar 2013-2014. Biodiversity and Nature Conservation Association, Yangon, Myanmar.

Aung, P.-P., Moses, S., Zaw, M.T., Naung, H.P., Htet, M.T. \& Aung, N.O.O. (2015) Monitoring Programme for the Critically Endangered Spoon-Billed Sandpiper on its Most Important Wintering Grounds in Myanmar. Biodiversity and Nature Conservation Association, Yangon, Myanmar.

Aung, P.-P., Moses, S., Zaw, M.T., Naung, H.P., Htet, M.T. \& Aung, N.O.O. (2016) Monitoring Programme for the Critically Endangered Spoon-Billed Sandpiper on its Most Important Wintering Grounds in Myanmar. Biodiversity and Nature Conservation Association, Yangon, Myanmar.

Aung, P.-P., Moses, S., Zaw, M.T., Naung, H.P., Htet, M.T. \& Aung, N.O.O. (2017) Monitoring of Migratory Shore Birds Survey in the Gulf of Mottama. Community-Led Coastal Management Gulf of Mottama Project. Biodiversity and Nature Conservation Association, Yangon, Myanmar.

Barsi, J.A., Lee, K., Kvaran, G., Markham, B.L. \& Pedelty, J.A. (2014) The spectral response of the Landsat-8 Operational Land Imager. Remote Sensing, 6, 10232-10251.

Birdife International (2017) Calidris pygmaea (amended version of 2017 assessment). The IUCN Red List of Threatened Species 2017: e.T22693452A117520594. Http://dx.doi.org/10.2305/IUCN.UK.20173.RLTS.T22693452A117520594.en [accessed 23 January 2018].

Clark, N., Pain, D. \& Green, R. (2014) Saving the spoon-billed sandpiper: an update on the conservation programme. British Birds, $107,467-475$.

Clark, N.A., Anderson, G.Q.A., Li, J., Syroechkovskiy, E.E., Tomkovich, P.S., Zöckler, C. et al. (2018) First formal estimate of the world population of the Critically Endangered spoon-billed sandpiper Calidris pygmaea. Oryx, 52, 137-146.

Htin Hla, T. \& Eberhardt, K. (2011) New hope from Nan Thar Island and Bay of Mottama. Spoon-billed Sandpiper Task Force News Bulletin, 6, 19-20.

Kirby, J. (2010) Review 2: Review of Current Knowledge of Bird Flyways, Principal Knowledge Gaps and Conservation Priorities. CMS Scientific Council: Flyway Working Group Reviews.
United Nations Environment Programme Convention on the Conservation of Migratory Species of Wild Animals, Bonn, Germany.

Mackinnon, J., Verkuil, Y.I. \& Murray, N. (2012) IUCN Situation Analysis on East and Southeast Asian Intertidal Habitats, with Particular Reference to the Yellow Sea (Including the Bohai Sea). Occasional Paper of the IUCN Species Survival Commission No. 47. IUCN, Gland, Switzerland, and Cambridge, UK.

Martinez, J. (2016) Massive loss of wetland habitat and rampant illegal mistnetting observed near Wenling city, Zhejiang province, China, May 2015. Spoon-billed Sandpiper Task Force News Bulletin, $16,19-21$.

Martinez, J. \& Lewthwaite, R. (2013) Rampant shorebird trapping threatens spoon-billed sandpiper Eurynorhynchus pygmeus in south-west Guangdong, China. Birding Asia, 19, 26-30.

Pain, D., Green, R. \& Clark, N. (2011) On the edge: can the spoonbilled sandpiper be saved? British Birds, 104, 350-363.

Peng, H.-B., Anderson, G.Q.A., Chang, Q., Choi, C.-Y., Chowdhury, S.U., Clark, N.A. et al. (2017) The intertidal wetlands of southern Jiangsu province, China-globally important for spoon-billed sandpipers and other threatened waterbirds, but facing multiple serious threats. Bird Conservation International, 27, 305-322.

Piersma, T., Lok, T., Chen, Y., Hassell, C.J., Yang, H.-Y., Boyle, A. et al. (2015) Simultaneous declines in summer survival of three shorebird species signals a flyway at risk. Journal of Applied Ecology, 53, 479-490.

Piersma, T., Chan, Y.-C., Mu, T., Hassell, C.J., Melville, D.S., PENG, H.-B. et al. (2017) Loss of habitat leads to loss of birds: reflections on the Jiangsu, China, coastal development plans. Wader Study, 124, 93-98.

Tomkovich, P., Syroechrovskiy, E., Yakushev, N., Loktionov, E., Digby, R. \& Shepelev, I. (2016) Spoon-billed sandpipers in Meinypilgyno: update of the 2016 breeding season. Spoon-billed Sandpiper Task Force News Bulletin, 16, 13-15.

Zöckler, C., Syroechrovsky, E.E. \& Atrinson, P.W. (2010a) Rapid and continued decline in the spoon-billed sandpiper Eurynorhynchus pygmeus indicates imminent extinction unless conservation action is taken. Bird Conservation International, 20, 95-111.

Zöckler, C., Htin Hla, T., Clark, N., Syroechkovsky, E., Yakushev, N., Daengphayon, S. \& Robinson, R. (2010b) Hunting in Myanmar is probably the main cause of the decline of the spoon-billed sandpiper Calidris pygmeus. Wader Study Group Bulletin, 117, 1-8.

Zöckler, C., Naing, T.Z., Moses, S., Soe, Y.N. \& Htin Hla, T. (2014) The importance of the Myanmar coast for water birds. Stilt, $66,37-51$.

Zöckler, C., Beresford, A.E., Bunting, G., Chowdhury, S.U., Clark, N.A., Fu, V.K. et al. (2016) The winter distribution of the spoon-billed sandpiper Calidris pygmaeus. Bird Conservation International, 26, 476-489. 